University of South Florida

DIGITAL COMMONS

Digital Commons @ University of

@ UNIVERSITY OF SOUTH FLORIDA

South Florida

USF Tampa Graduate Theses and Dissertations

USF Graduate Theses and Dissertations

$11-6-2009$

\title{
Effects of Expectancies and Coping on Pain-Induced Motivation to Smoke
}

Joseph W. Ditre

University of South Florida

Follow this and additional works at: https://digitalcommons.usf.edu/etd

Part of the American Studies Commons

\section{Scholar Commons Citation}

Ditre, Joseph W., "Effects of Expectancies and Coping on Pain-Induced Motivation to Smoke" (2009). USF Tampa Graduate Theses and Dissertations.

https://digitalcommons.usf.edu/etd/1934

This Dissertation is brought to you for free and open access by the USF Graduate Theses and Dissertations at Digital Commons @ University of South Florida. It has been accepted for inclusion in USF Tampa Graduate Theses and Dissertations by an authorized administrator of Digital Commons @ University of South Florida. For more information, please contact digitalcommons@usf.edu. 
Effects of Expectancies and Coping on Pain-Induced Motivation to Smoke

by

Joseph W. Ditre

A thesis submitted in partial fulfillment

of the requirements for the degree of

Doctor of Philosophy

Department of Psychology

College of Arts and Sciences

University of South Florida

\author{
Major Professor: Thomas H. Brandon, Ph.D. \\ Paul B. Jacobsen, Ph.D. \\ David J. Drobes, Ph.D. \\ Mark S. Goldman, Ph.D. \\ Jamie Lynn Goldenberg, Ph.D.
}

Date of Approval:

November 6, 2009

Keywords: smoking, experimental pain, craving, tobacco, social-cognitive theory

(C) Copyright 2009, Joseph W. Ditre 
Table of Contents

List of Tables

iv

List of Figures $\quad$ V

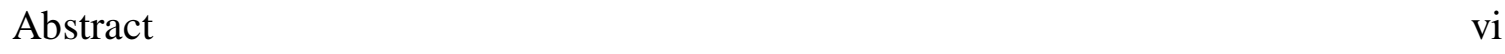

Introduction $\quad 1$

Smoking-related outcome expectancies $\quad 4$

Coping behaviors 4

Coping self-efficacy and outcome expectancies 5

$\begin{array}{ll}\text { Method } & 7\end{array}$

$\begin{array}{lr}\text { Participants } & 8\end{array}$

Design $\quad 8$

$\begin{array}{lr}\text { Measures } & 8\end{array}$

$\begin{array}{ll}\text { Apparatus } & 11\end{array}$

Cold pressor 11

$\begin{array}{ll}\text { Manipulations } & 11\end{array}$

Coping Enhancement 11

$\begin{array}{lr}\text { Expectancy Challenge } & 12\end{array}$

$\begin{array}{ll}\text { Procedure } & 13\end{array}$

Results 16

Baseline Measures $\quad 16$

$\begin{array}{ll}\text { Manipulation Checks } & 16\end{array}$

Expectancy Challenge 16

Coping Enhancement 16

Primary Analyses 17

$\begin{array}{ll}\text { Self-reported urge to smoke } & 17\end{array}$

$\begin{array}{ll}\text { Latency to smoke } & 18\end{array}$

Number of puffs taken and total time spent smoking $\quad 19$

$\begin{array}{ll}\text { Additional Analyses } & 20\end{array}$

Impression management $\quad 20$

$\begin{array}{ll}\text { Affect } & 20\end{array}$

$\begin{array}{ll}\text { Mediation } & 21\end{array}$

Pain and cold pressor tolerance $\quad 21$ 
Table of Contents (Continued)

Discussion $\quad 22$

Pain-coping behaviors $\quad 23$

Expectancies for pain coping/reduction via smoking 24

References $\quad 29$

$\begin{array}{ll}\text { Appendices } & 37\end{array}$

Appendix A: Questionnaire of Smoking Urges-Brief 38

Appendix B: Pain and Smoking Expectancies Measure $\quad 39$

Appendix C: Perceived Self-Efficacy to Manage Pain 40

Appendix D: Positive and Negative Affect Schedule 43

Appendix E: Balanced Inventory of Desirable Responding - IM 44

Appendix F: Bogus Personality Measure $\quad 45$

Appendix G: Numerical Rating Scale $\quad 46$

Appendix H: Smoking Status Questionnaire $\quad 47$

Appendix I: Demographic Questionnaire 48

About the Author $\quad$ End Page 


\section{List of Tables}

Table 1 Means (Standard Errors) for Post-Pain Induction Measures of Smoking Motivation 


\section{List of Figures}

Figure $1 \quad$ Covariate-adjusted mean urge ratings (and standard errors) as a function of the Expectancy Challenge $x$ Coping Enhancement interaction

Figure 2 Conceptualized causal relationship between pain and motivation to smoke as a function of smoking-related outcome expectancies and use of pain coping behaviors 


\title{
Effects of Expectancies and Coping on Pain-Induced Motivation to Smoke
}

Joseph W. Ditre

\begin{abstract}
The prevalence of tobacco smoking among persons with recurrent pain is approximately twice that observed in the general population. Smoking has been associated with the development and exacerbation of several chronically painful conditions. Conversely, there is both experimental and cross-sectional evidence that pain is a potent motivator of smoking. A recent study provided the first evidence that laboratory-induced pain could elicit increased craving and produce shorter latencies to smoke (Ditre \& Brandon, 2008). To further elucidate interrelations between pain and smoking, and to identify potential targets for intervention, the current study tested whether several constructs derived from social-cognitive theory influence the causal pathway between pain and increased motivation to smoke. Smokers $(N=132)$ were randomly assigned to one of four conditions in this $2 \times 2$ between-subjects experimental design. Results indicated that manipulations designed to (a) challenge smoking-related outcome expectancies for pain reduction, and (b) enhance pain-related coping, each produced decreased urge ratings and increased latencies to smoke, relative to controls.
\end{abstract}




\section{Introduction}

Cigarette smoking remains the leading preventable cause of morbidity and mortality in the United States, accounting for more than 435,000 deaths each year and an estimated $\$ 193$ billion in annual medical expenses and lost productivity (CDC, 2008a, 2008b). The recently updated U.S. Department of Health and Human Services' Clinical Practice Guidelines for Treating Tobacco Dependence identified smokers with comorbid medical conditions as important targets for tobacco cessation (Fiore et al., 2008). We have further proposed that some medical conditions and their associated symptoms (i.e., pain) may also serve to increase, reinforce, or prolong tobacco dependence (Ditre \& Brandon, 2008).

Pain and smoking have been linked in both the clinical and empirical literature for decades. In fact, the prevalence of smoking among individuals who live with pain has been estimated to be greater than twice that of the general population (e.g., Jamison, Stetson, \& Parris, 1991; Michna et al., 2004). Studies of interrelationships between pain and smoking can be usefully dichotomized into investigations of either the effects of smoking on pain (e.g., smoking causing, increasing, or inhibiting pain), or the effects of pain on smoking (e.g., pain increasing smoking motivation), with the latter direction having received far less empirical attention (for a comprehensive review of these topics see Ditre \& Brandon, under review). 
Tobacco smoking has been associated with the occurrence, protraction, and exacerbation of several chronically painful conditions, including musculoskeletal pain, rheumatoid arthritis, oral pain, headache activity, and fibromyalgia (e.g., Aamodt, Stovner, Hagen, Brathen, \& Zwart, 2006; Albano, Santana-Sahagun, \& Weisman, 2001; Eriksen, Brage, \& Bruusgaard, 1997; Palmer, Syddall, Cooper, \& Coggon, 2003; Payne et al., 1991; Riley, Tomar, \& Gilbert, 2004). However, consistent with experimental evidence of acute smoking-related analgesia (e.g., Girdler et al., 2005; Jamner, Girdler, Shapiro, \& Jarvik, 1998), there is reason to believe that some smokers may be motivated to use tobacco in response to pain. Indeed, researchers have proposed that the avoidance, relief, or both, of pain may be a powerful behavioral reinforcer and an important mechanism in the maintenance of smoking (Fertig, Pomerleau, \& Sanders, 1986; Jarvik, Caskey, Rose, Herskovic, \& Sadeghpour, 1989; Pomerleau, 1986; Silverstein, 1982).

Support for the hypothesis that pain may promote smoking can be derived from cross-sectional studies which have demonstrated that smokers experiencing chronic or intermittent pain are more likely to be current tobacco users and to be diagnosed as nicotine dependent (Zvolensky, McMillan, Gonzalez, \& Asmundson, 2009). These individuals also tend to report greater motivation to smoke (Jamison et al., 1991) and increased cigarette consumption (Hahn, Rayens, Kirsh, \& Passik, 2006). Positive correlations between pain severity and smoking rates have also been reported (e.g., Davidson, Davidson, Tripp, \& Borshch, 2005; Ditre et al., under review; Fishbain et al., 2007; Waldie, McGee, Reeder, \& Poulton, 2008). It is important to note, however, that the apparent covariance between pain and smoking may reflect either smokers' use of 
tobacco to cope with pain, the contribution of smoking to the occurrence or aggravation of painful conditions, or both. Therefore, to address the issue of causality, Ditre and Brandon (2008) conducted an experimental investigation to test the effect of situational pain on motivation to smoke tobacco.

Ditre and Brandon (2008) hypothesized that laboratory-induced cold-pressor pain would increase urges to smoke and immediate smoking behavior. In that betweensubjects design, 132 smokers were randomly assigned to either pain (cold pressor test, 0$1^{\circ} \mathrm{C}$ ) or no pain (room-temperature water) conditions. Following the pain manipulation, all participants completed measures of mood and desire to smoke, and were given the opportunity to smoke one of their own cigarettes. As hypothesized, participants who underwent pain induction reported significantly greater urges to smoke and demonstrated quicker latencies to light a cigarette than participants who did not experience pain. In addition, the effect of pain on craving to smoke was partially mediated by pain-induced negative affect. This study provided the first experimental evidence that situational pain is a causal motivator of smoking.

To better understand interrelationships between pain and smoking, and to identify important targets for intervention, there is a need to examine theory-driven mechanisms that may underlie the causal relation between situational pain and increased motivation to smoke. In examining the respective pain and smoking literature, several social-cognitive constructs (Bandura, 1977, 1986) were observed as particularly salient across these domains (i.e., smoking-related outcome expectancies, coping behaviors, and coping selfefficacy/outcome expectancies). 


\section{Smoking-Related Outcome Expectancies}

Cognitive processes, including drug and alcohol outcome expectancies, are prominent among theories of addiction motivation (Brandon, Herzog, Irvin, \& Gwaltney, 2004). Such expectancies may be conceptualized as dynamic, memory-based information templates that become part of anticipatory, automatic behavioral sequences leading to the use of substances, including tobacco (Goldman, 1999, 2002). Indeed, many theoretical models have incorporated outcome expectancies into the causal chain that leads to drug use and relapse (e.g., Brandon, Wetter, \& Baker, 1996; Cooper, Russell, \& George, 1988; Marlatt \& Gordon, 1985). Smoking-related outcome expectancies have been associated with multiple indices of smoking motivation, and there is clear evidence that heavier, more dependent smokers hold more positive expectancies about the consequences of smoking than do lighter smokers or nonsmokers (Brandon, Juliano, \& Copeland, 1999). There is also evidence that smoking-related outcome expectancies, particularly those related to negative affect reduction, can be experimentally challenged and successfully manipulated (Copeland \& Brandon, 2000).

\section{Coping Behaviors}

Coping behaviors represent a vast collection of cognitive and behavioral strategies that individuals use to deal with or manage specific stressors such as pain. For example, several cognitive strategies (e.g., cognitively transforming noxious stimulation and utilizing distraction) appear to be effective for reducing experimental pain (Devine \& Spanos, 1990; Rokke, Fleming-Ficek, Siemens, \& Hegstad, 2004). Tobacco and other substances have been hypothesized to help people cope with stress by regulating affect 
(Brandon et al., 1996; Kassel, Stroud, \& Paronis, 2003), facilitating distraction (Brandon \& Baker, 1991; Steele \& Josephs, 1990), or enhancing performance (Heishman, 1999). One such model posits that people become psychologically reliant on substances they use to cope with stressors (Wills \& Hirky, 1996). Using substances to cope may hinder the development of superior coping strategies and lead to greater dependence (Cooper et al., 1988).

\section{Coping Self-Efficacy and Outcome Expectancies}

According to social learning theory, effective pain coping is likely a function of both believing that the behavior can be successfully executed (i.e., coping self-efficacy), and that engagement of the coping response will lead to amelioration of pain (i.e., coping outcome expectancy). Indeed, research has demonstrated that using a coping strategy (particularly when enhanced with positive self-efficacy feedback) can effectively reduce ratings of pain severity in both clinical and experimental settings (e.g., Devine \& Spanos, 1990; Haythornthwaite, Menefee, Heinberg, \& Clark, 1998; Jensen, Turner, \& Romano, 1991; Keefe et al., 1997; Marino, Gwynn, \& Spanos, 1989; Rosenstiel \& Keefe, 1983).

The main goal of the current study was to test experimentally, these socialcognitive constructs that may influence smokers' responses to situational pain. Specifically, we hypothesized that manipulations designed to (a) challenge smokingrelated outcome expectancies for pain coping/reduction (herein referred to as the Expectancy Challenge), and (b) introduce and enhance pain-related coping (herein referred to as the Coping Enhancement), would each reduce post-pain induction motivation to smoke (as indexed by self-reported urge to smoke and immediate smoking 
behavior), when compared with control conditions.

The Expectancy Challenge was designed to manipulate a construct that has been shown in the smoking literature to influence craving and smoking behavior (e.g., Brandon et al., 1999; Copeland \& Brandon, 2000), whereas the Coping Enhancement was designed to manipulate variables (i.e., coping, coping self-efficacy, and pain-related outcome expectancies) that have been shown in the pain literature to predict various indices of pain reactivity (e.g., Devine \& Spanos, 1990; Rokke et al., 2004). Thus, the current study sought to integrate empirical literature from the domains of smoking and pain, respectively.

This study was also intended to serve as an analogue test of variables that may merit further investigation for their capacity to influence the development of interventions for persons with comorbid pain and addiction disorders. Indeed, the current experiment represents the second step in a programmatic line of research designed to address both internal and external validity requirements in a cumulative fashion. The ultimate goals of this work are to better understand the relationship between pain and smoking, and to develop smoking prevention, cessation, and relapse-prevention interventions for tobacco-dependent smokers who live with pain. 


\section{Method}

\section{Participants}

Newspaper advertisements were used to recruit 132 smokers (50\% female). The sample size was selected to allow for adequate power (i.e., .81) to detect 'medium' sized effects at the two-tailed $\alpha=.05$ level (Cohen, 1988). Prospective participants were screened for the following inclusion criteria: between 18 and 65 years of age $(M=39.58$; $S D=9.91)$, smoke at least 15 cigarettes per day $(M=24.76 ; S D=13.23)$, and have a presession expired carbon monoxide concentration of at least 8ppm $(M=25.86 ; S D=$ 10.97). Prospective participants were also screened for the following exclusion criteria: the presence of contraindicative medical conditions (i.e., acute pain, chronic pain, diabetes, epilepsy, and recent injury), and use of prescription medications for pain management, anxiety, heart problems, or blood circulation problems. Individuals who failed to meet all of the inclusion criteria or endorsed any of the exclusion criteria were not enrolled in the study. Fagerström Test for Nicotine Dependence (FTND; Heatherton, Kozlowski, Frecker, \& Fagerstrom, 1991) scores indicated that the current sample was moderately to highly dependent on tobacco $(M=6.68 ; S D=2.06)$. Participants were predominantly Caucasian (65.9\%) and African American (32.6\%), with 1.5\% identifying as American Indian or Alaskan Native. Of the full sample, 11.4\% were Hispanic/Latino. 


\section{Design}

Participants were randomly assigned to one of four conditions, stratified by gender, in this 2 (Expectancy Challenge) X 2 (Coping Enhancement) crossed-factorial between-subjects design. Thus, 33 participants were randomized to each experimental condition. Dependent measures included self-reported urge to smoke and observation of immediate smoking behavior. Participants were compensated $\$ 30$ for approximately 1.5 hours of their time.

\section{Measures}

Questionnaire of Smoking Urges-Brief (QSU-B; Cox, Tiffany, \& Christen, 2001). The QSU-B is a widely used 10-item measure of immediate urge or craving to smoke a cigarette. Participants were asked to indicate how strongly they agreed or disagreed with each item by completing a Likert-type scale that ranged from 0 (strongly disagree) to 6 (strongly agree), with higher scores indicating stronger smoking urges. In the current study, the QSU-B demonstrated excellent internal consistency $(\alpha=.95)$.

Smoking behavior. As a behavioral index of smoking motivation, participants were given an opportunity to smoke following pain induction. Smoking was recorded with a discrete digital video camera and independently scored by two trained raters. Measures of primary interest included latency to light a cigarette, number of puffs taken, and total time spent smoking. Kappa statistics were computed to determine consistency among raters. Interrater reliability for all three measures of smoking behavior was excellent $(\mathrm{Ks} \geq 0.96)$. This procedure demonstrated construct validity in our previous study of pain-related smoking (Ditre \& Brandon, 2008). 
Pain and Smoking Expectancies Measure (PSE). Developed for a previous study (Ditre \& Brandon, 2008), this 5-item scale assesses smokers' expectancies that smoking will help them cope with and/or reduce pain. Participants rated how true each statement was for them by endorsing a number from 0 ("completely unlikely") to 9 (“completely likely"). This measure was highly reliable ( $\alpha=.96)$, and served as a manipulation check for the Expectancy Challenge.

Perceived Self-Efficacy to Manage Pain (PSEMP; Bandura, Cioffi, Taylor, \& Brouillard, 1988). The PSEMP served as a check for the Coping Enhancement manipulation, and consisted of two scales. The first scale, designed to measure perceived self-efficacy to withstand pain, included 22 items representing increasing lengths of coldpressor tolerance (from 5 seconds to 5 minutes), and participants were asked to rate their confidence (from 0-100\%) in keeping their hand submerged for each duration of time. The second scale was developed to measure perceived self-efficacy to reduce and/or cope with pain. Participants were asked to rate their confidence (from 0-100\%) in executing three degrees of pain reduction/coping (i.e., small, moderate, or large) across four severities of pain (ranging from dull to excruciating), for a total of 12 items. Consistent with previous research, total scores for each of the scales were obtained by summing the individual confidence ratings and dividing by the number of scale items (e.g., Bandura et al., 1988). Each of the two PSEMP scales demonstrated excellent internal consistency ( $\alpha$ $=.97$ and $\alpha=.94$, respectively).

Positive And Negative Affect Schedule (PANAS; Watson, Clark, \& Tellegen, 1988). The PANAS is comprised of two orthogonal mood scales (positive and negative), 
each containing 10 items. Participants were asked to rate their current mood on a 5-point Likert scale, ranging from "very slightly or not at all" to "extremely." The ratings of each mood scale were summed, with higher scores indicating stronger affect. Both the positive $(\alpha=.81)$ and negative $(\alpha=.84)$ affect scales demonstrated good reliability.

Balanced Inventory of Desirable Responding - Impression Management (Paulhus, Robinson, Shaver, \& Wrightsman, 1991). The 20-item BIDR-IM was included to test for potential associations between self-report ratings and proclivity towards biased responding and impression management. This measure demonstrated adequate internal consistency $(\alpha=.74)$.

Bogus Personality Measure (BPM). This 10-item adaptation of Byrne's (1961) Repression-Sensitization scale was used as a bogus measure to provide purported feedback designed to enhance participants' expectancies for successful pain coping, specifically with regard to their utilization of a distraction-based coping strategy. The BPM was used for a similar purpose in a previous study of cold pressor pain induction (Marino et al., 1989).

Numerical Rating Scale (NRS; Dworkin et al., 2005). The NRS is an 11-point numerical rating scale of pain intensity. Participants were asked to circle the number that best describes their pain, at its worst, since placing their hand in the cold water $(0=$ "No pain" and $10=$ "Pain as bad as you can imagine").

Smoking Status Questionnaire (SSQ). This form was used to assess smoking status, smoking history, and other smoking-related variables. The SSQ also included the Fagerström Test for Nicotine Dependence, a reliable and valid measure of nicotine 
dependence (Heatherton, Kozlowski, Frecker, \& Fagerstrom, 1991).

Demographic Questionnaire (DQ). The DQ assessed basic demographic information, including gender, age, marital status, race, ethnicity, and household income.

Exhaled Carbon Monoxide (CO). The measurement of exhaled $\mathrm{CO}$ level correlates closely with blood carboxyhaemoglobin concentration and provides an immediate, non-invasive method of assessing smoking status.

Apparatus

Cold pressor. This method of pain stimulation is believed to replicate some subjective qualities frequently observed in clinical pain patients, including the unpleasantness associated with chronically painful conditions (Keogh, Hatton, \& Ellery, 2000; Rainville, Feine, Bushnell, \& Duncan, 1992). Participants were asked to immerse their non-dominant hand into room-temperature water for two minutes (to standardize limb temperature $)$ prior to immersing the same hand into a cold-water bath $\left(0-1^{\circ}\right.$ Celsius $)$ until they felt it too uncomfortable to continue. The cold pressor used in the current study was developed by technicians at Moffitt Cancer Center and consisted of an insulated cooler unit with a perforated screen (to keep the water and ice separate) and a 12-volt bilge pump (to circulate the water).

\section{Manipulations}

Coping Enhancement. Participants randomized to Coping Enhancement conditions were instructed to utilize a pain coping task and procedure that was previously demonstrated to influence subjective ratings of pain reactivity among participants undergoing cold pressor pain-induction (Marino et al., 1989). This distraction-based 
coping task required participants to listen to and repeat aloud letters (i.e., lettershadowing) at a rate of three letters every two seconds before (for 15 seconds), during, and after (for 15 seconds) submerging their hand into the cold pressor. The letters were presented in random order and participants were given a 30-second pre-pain induction practice trial. To enhance self-efficacy for coping and to increase expectancies for successful pain coping, participants received purported feedback (ostensibly derived from responses to the BPM) that this strategy would be effective for them. Control participants (i.e., No-Coping Enhancement) were not instructed to utilize the distraction task during pain-induction and received no BPM feedback.

Expectancy Challenge. We intended to reduce outcome expectancies that smoking can effectively help one cope with pain by utilizing a video-based expectancy challenge. A similar video manipulation, previously developed within our lab, was shown to decrease participant expectancies that smoking is an effective means to cope with negative affect (Copeland \& Brandon, 2000). For the purpose of the current study, two videos (each 5 minutes in length) were produced: one video designed to reduce expectancies for reducing or coping with pain via smoking (Expectancy Challenge), and one control content video (No-Expectancy Challenge). The Expectancy Challenge video consisted of an expert presenting information regarding demonstrated associations between smoking and pain (e.g., the relationship between smoking and the development/exacerbation of chronic pain, and nicotine's capacity to narrow attention so that one may be more likely to focus on the pain). The information portion of the video was followed by brief "participant" testimonials that, in their experience, smoking was 
not effective for pain coping. Lastly, the testimonials were followed by a brief quiz (true/false) to reinforce the video content. The No-Expectancy Challenge video consisted of the same expert presenting information on the history of tobacco (e.g., the historical role of Columbus and other early explorers in the proliferation of tobacco use). In similar fashion to the experimental video, this information was followed by brief "participant" reactions (e.g., that they were previously unaware of this information), and a brief quiz to reinforce the video content.

\section{Procedure}

Trained operators screened prospective participants. Eligible participants were asked to refrain from using any non-prescription pain medications for 24 hours prior to their appointment. Eligible participants were also asked to smoke one cigarette exactly one hour prior to their appointment and none thereafter (to standardize smoking behavior prior to the experiment). Upon arrival, informed consent and HIPAA authorization were obtained. Participants were then asked when they smoked their last cigarette. If participants reported that it had been less than 40 minutes or greater than 80 minutes since their last cigarette, they were excluded from the study.

Upon study initiation, the experimenter collected participant cigarettes (to be returned at the end of the study) and administered baseline measures (e.g., QSU-B1, PANAS1, BPM; BIDR-IM, DQ, SSQ). Once baseline measures were collected, participants were exposed to the cold pressor for 5 seconds (CP1) to provide a frame of reference for completing pre-manipulation measures of pain intensity, perceived self- 
efficacy for managing pain, and expectancies for reducing or coping with pain via smoking (i.e., NRS1, PSEMP1, PSE1).

Participants were then randomized to one of the four experimental conditions. The experimenter always administered the Expectancy Challenge (or No-Expectancy

Challenge) before administering the Coping Enhancement (or No-Coping Enhancement). The order of administration was selected so that instructions and training for utilizing the coping strategy would occur in close proximity to the full cold pressor test (CP2).

Following the manipulations, participants completed the PSEMP2 and PSE2.

Next, all smokers underwent the full cold pressor test (CP2). When participants indicated that they were no longer able or willing to tolerate the cold pressor by removing their hand, they were asked to complete post-pain induction measures of pain severity, urge to smoke, and affect (i.e., NRS2, QSUB2, PANAS2). Next, the behavioral measure of smoking motivation was collected. Specifically, participants were informed that the experimenter had to leave the room for approximately 10 minutes to prepare for the next phase of the study. Participants were then told that during this time they were welcome to smoke as much or as little of their one cigarette as they would like, but to please take at least one puff before the experimenter returned. The experimenter then placed down a previously hidden tray, which contained participants' own lighter and a single cigarette placed in a glass ashtray (both the lighter and cigarettes were collected at the beginning of the study). At this point, the experimenter left the room to observe smoking behavior via discrete video monitoring. When the experimenter returned, participants completed 
some additional secondary measures (i.e., not central to the primary hypotheses), provided a second CO sample, and were debriefed and compensated. 
Results

Baseline Measures

As expected, Analysis of variance (ANOVA) revealed no significant differences (all $p \mathrm{~s} \geq .45$ ) across the four experimental conditions on baseline measures of demographics (DQ), smoking status (SSQ), urge to smoke (QSU-B), negative affect (PANAS-NA), positive affect (PANAS-PA), and impression management (BIDR-IM).

Also as expected, we observed no differences (all $p \mathrm{~s} \geq .15$ ) on pre-manipulation measures of expectancies for pain-coping or reduction via smoking (PSE) and perceived selfefficacy to manage pain (PSEMP).

Manipulation Checks

Expectancy Challenge. To examine the effect of the Expectancy Challenge on PSE scores, Analysis of covariance (ANCOVA; controlling for baseline PSE) was conducted. As expected, participants who viewed the experimental video reported significantly lower positive outcome expectancies for pain-coping and reduction via smoking (Expectancy Challenge: $M=5.40 ; S E=.94$ ) than did participants who were randomized to view the control video (No-Expectancy Challenge: $M=17.72 ; S E=.94$ ), $F(1,127)=86.45, p<.001$.

Coping Enhancement. A similar ANCOVA was conducted to examine the effect of the Coping Enhancement on perceived self-efficacy to withstand pain (PSEMP Scale 1) and perceived self-efficacy to reduce and/or cope with pain (PSEMP Scale 2). Also as 
expected, participants randomized to utilize a distraction-based coping strategy during pain induction reported significantly greater confidence in their ability to tolerate $[F(1$, $127)=23.67, p<.001, f=.15]$ and reduce/cope with cold-pressor pain $[F(1,127)=$ $23.89, p<.001, f=.16]$ relative to those not instructed to cope during pain induction. Primary Analyses

Self-reported urge to smoke. Independent and synergistic effects of the Expectancy Challenge and the Coping Enhancement on post-pain induction urge to smoke were tested via ANCOVA (controlling for baseline urge). Effect sizes, indexed as $f$, were calculated for significant $\mathrm{F}$ tests. According to Cohen (1988), $f$ values of $.10, .25$, and .40 can be considered small, medium, and large, respectively. Three extreme values (i.e., urge ratings greater than two SDs from the mean) were excluded. Analysis revealed main effects for both the Expectancy Challenge $[F(1,124)=26.09, p<.001, f=.43]$ and Coping Enhancement $[F(1,124)=8.87, p<.01, f=.24]$. As seen in Table 1, urge ratings were suppressed among participants who viewed an experimental video designed to diminish positive outcome expectancies for pain-coping via smoking (Expectancy Challenge), relative to those who viewed a control video (No-Expectancy Challenge). Urge ratings were also suppressed among participants who were instructed to use a distraction-based coping strategy during pain induction (Coping Enhancement), relative to those who were not instructed to cope (No-Coping Enhancement).

As depicted in Figure 1, analysis also revealed a significant Expectancy Challenge $\mathrm{x}$ Coping Enhancement interaction $[F(1,124)=6.39, p=.01, f=.20]$. Post hoc Fisher's LSD tests showed that urge ratings were highest for participants randomized to the No- 
Expectancy Challenge + No-Coping Enhancement condition, relative to each of the other three experimental conditions (all $p \mathrm{~s}<.001$ ). None of the remaining pairwise comparisons reached significance (see Table 1). Thus, although the Expectancy Challenge and the Coping Enhancement were each sufficient to reduce craving to smoke, these manipulation effects were not additive.

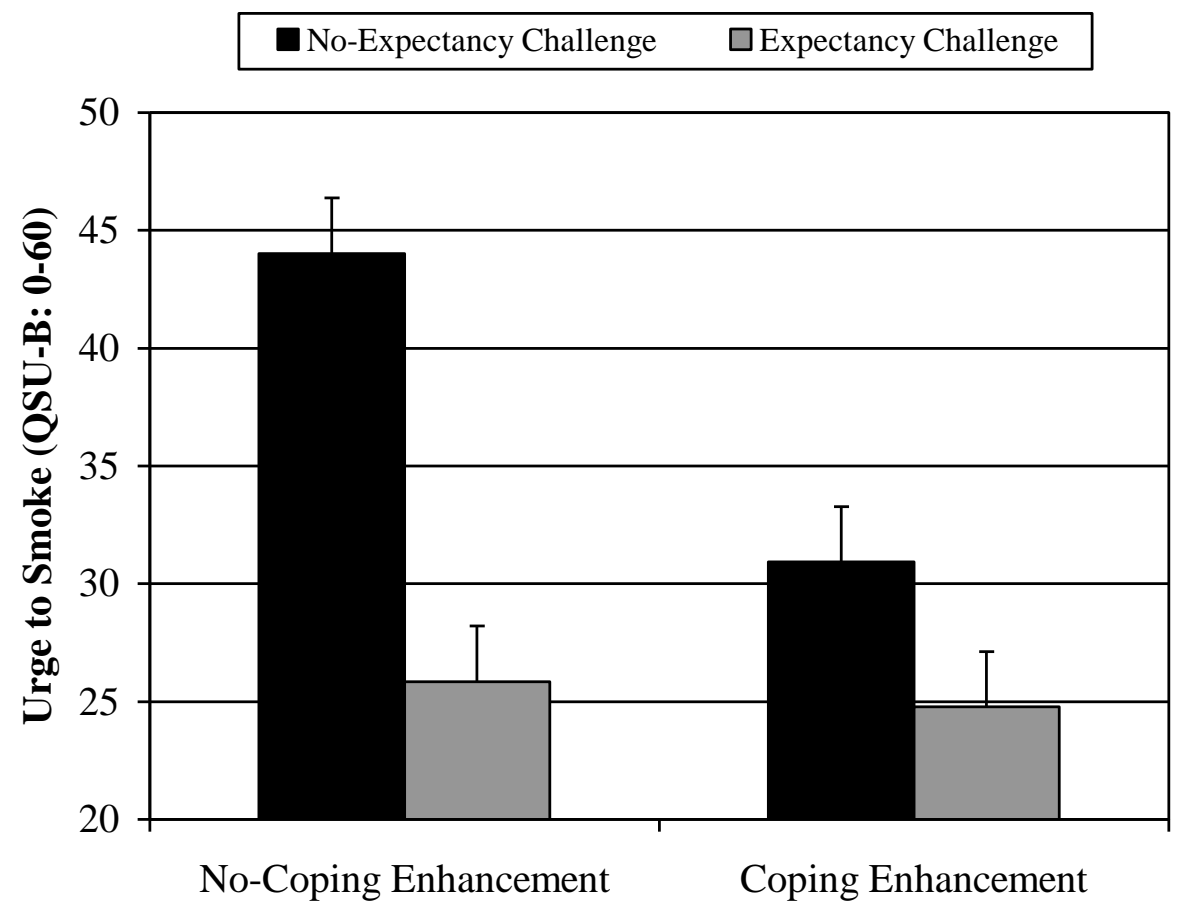

Figure 1. Covariate-adjusted mean urge ratings (and standard errors) as a function of the Expectancy Challenge $\mathrm{x}$ Coping Enhancement interaction.

Latency to smoke. ANOVA was conducted to examine effects of the Expectancy Challenge and the Coping Enhancement on post-pain induction latency to light a cigarette. Scores for 11 extreme values (i.e., latencies greater than two SDs from the mean) and 8 participants who were off camera when they lit their cigarette were 
excluded. Removal of extreme values resulted in substantially improved skewness $(S=$ 5.77 to $S=1.20$ ) and kurtosis ( $K=35.65$ to $K=1.50$ ) statistics for the latency variable. Excluded participants were fairly evenly distributed across conditions.

As with urge, latency analysis revealed expected main effects for both the Expectancy Challenge $[F(1,109)=4.43, p=.04, f=.20]$ and the Coping Enhancement $[F(1,109)=5.82, p=.02, f=.23]$. The Expectancy Challenge $\mathrm{x}$ Coping Enhancement interaction was not significant $(p=.97)$. As seen in Table 1 , smokers randomized to Expectancy Challenge and Coping Enhancement conditions demonstrated the longest latencies, with shorter latencies observed for those randomized to control conditions. Number of puffs taken and total time spent smoking. Similar ANOVAs were performed to test for group differences on number of puffs taken and total time spent smoking. No extreme values were identified. Results indicated that smokers randomized to Expectancy Challenge conditions took significantly fewer puffs $[F(1,128)=5.41, p=$ $.02, f=.21]$ and spent less time smoking $[F(1,128)=5.53, p=.02, f=.21]$, relative to smokers randomized to No-Expectancy Challenge conditions (see Table 1). Coping Enhancement effects were not significant for number of puffs $[F(1,128)=0.21, p=.65, f$ $=.04]$ or time spent smoking $[F(1,128)=0.68, p=.41, f=.07]$, and no significant interactions were observed (both $p$ s $>.29$ ). 
Table 1

Means (Standard Errors) for Post-Pain Induction Measures of Smoking Motivation

Main Effects

\begin{tabular}{lcccccc} 
& Expectancy & No-Expectancy & Coping & No-Coping & \\
& Challenge & Challenge & & Enhancement & Enhancement & \\
& & & & & & \\
\hline Craving & $25.31(1.66)$ & $37.48(1.70)$ & $* *$ & $27.85(1.66)$ & $34.94(1.70)$ & $*$ \\
Latency & $5.90(0.91)$ & $3.19(0.92)$ & $*$ & $6.10(0.92)$ & $2.99(0.91)$ & $*$ \\
\# Puffs & $10.17(0.68)$ & $12.39(0.68)$ & $*$ & $11.06(0.68)$ & $11.50(0.68)$ & $\mathrm{ns}$ \\
Time Smoke & $244.3(16.1)$ & $297.8(16.1)$ & $*$ & $261.7(16.1)$ & $280.4(16.1)$ & $\mathrm{ns}$
\end{tabular}

Note. Craving = covariate-adjusted urge ratings (controlling for baseline QSU-B Total $=29.39$ ). Latency $=$ duration of time (in seconds) from when participants were given the opportunity to smoke until they lit their cigarette. \# Puffs = total number of puffs taken. Time Smoke $=$ total time spent smoking (in seconds). $* p<.05 . * * p<.001$.

\section{Additional Analyses}

Impression management. To test for potential bias in self-report responding, BIDR-IM scores were correlated with baseline, pre/post-manipulation, and pre/post-pain induction self-report measures. No significant correlations were found between these measures when tested either within or across experimental conditions.

Affect. To examine effects of the Expectancy Challenge and the Coping Enhancement on self-reported positive and negative affect, separate ANCOVAs were conducted (controlling for baseline PANAS scores). Analysis revealed that participants randomized to Coping Enhancement conditions reported greater post-pain induction positive affect $(M=31.02 ; S E=.79)$ than No-Coping Enhancement participants $(M=$ 28.47; $S E=.79), F(1,127)=5.03, p=.02, f=.15$. Conversely, there was no effect of the 
Expectancy Challenge on positive affect $(p=.89)$. There was also no effect of either manipulation on negative affect (both $p \mathrm{~s}>.60$ ).

Mediation. To follow up on our finding that Coping Enhancement participants reported greater post-pain induction positive affect, mediation analyses were conducted to determine whether urge ratings were suppressed among Coping Enhancement participants due to increased positive affect. Formal significance tests of the indirect effect of positive affect on urge to smoke (see Preacher \& Hayes, 2004) revealed no evidence of mediation.

Pain and cold pressor tolerance. We expected that smokers randomized to Coping Enhancement conditions would report less pain and keep their hand in the cold water for longer than would smokers randomized to No-Coping Enhancement conditions. Although we observed no differences in pain reporting $(M=7.49 ; S E=.19 ; p=.48)$, analysis did indicate that Coping Enhancement participants $(M=50.89 ; S E=6.35)$ were able to keep their hand submerged for substantially longer ( +21.01 seconds, $p=.02)$ than their No-Coping Enhancement counterparts $(M=29.88 ; S E=6.35)$. 


\section{Discussion}

The main goal of the current study was to determine whether the previously demonstrated causal pathway between situational pain and increased motivation to smoke (i.e., Ditre \& Brandon, 2008) could be disrupted by invoking social learning theory-based constructs known to influence smoking behavior and pain reactivity (i.e., smoking-related outcome expectancies, coping behaviors, and coping self-efficacy/outcome expectancies). Furthermore, these constructs were selected for their potential to inform the conceptualization and development of interventions for persons with comorbid pain and tobacco dependence disorders.

As hypothesized, participants randomized to experimental conditions designed to (a) challenge expectancies that smoking may help one cope with or reduce pain (Expectancy Challenge), or (b) introduce an effective pain coping strategy enhanced with positive self-efficacy and outcome expectancy feedback (Coping Enhancement), reported significantly lower smoking urges and demonstrated longer latencies to smoke following pain induction, relative to controls (No-Expectancy Challenge or No-Coping Enhancement, respectively). Expectancy Challenge smokers also took fewer puffs and spent less time smoking than No-Expectancy Challenge smokers.

Results further revealed an unexpected Expectancy Challenge x Coping Enhancement interaction for self-reported urge to smoke. However, this interaction appears to be removable (i.e., a non-crossover interaction). Pairwise comparisons were 
significant only when the No-Expectancy Challenge + No-Coping Enhancement condition was compared with each of the other three experimental conditions. This finding is consistent with the observed main effects in that any permutation of the active manipulations effectively suppressed craving relative to controls. In other words, the manipulation effects were not found to be additive or synergistic.

Based on these findings, and extrapolating from the extant pain and smoking literature, we conceptualized the following relationship between the constructs under investigation and the causal relation between pain and motivation to smoke.

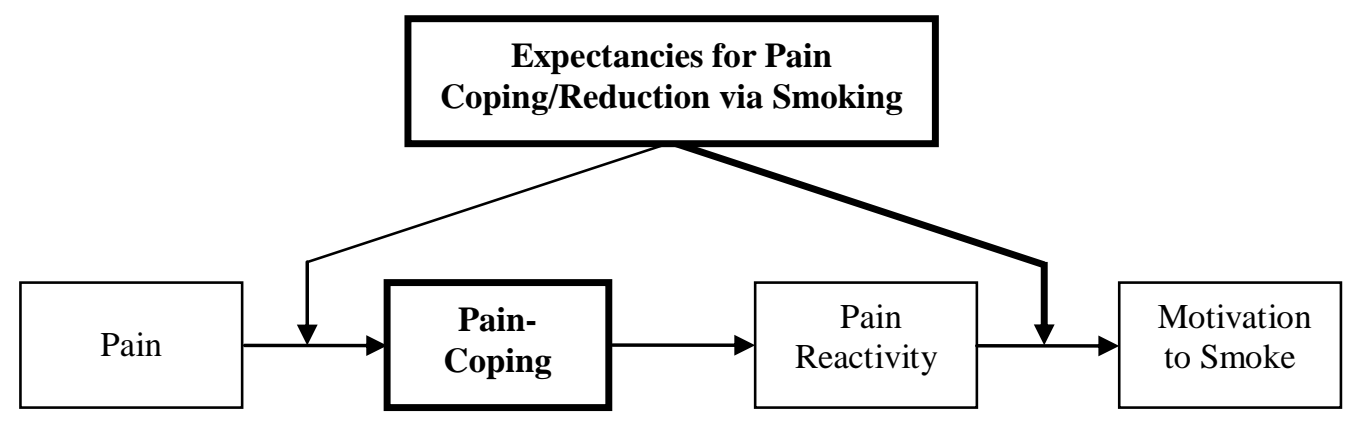

Figure 2. Conceptualized causal relationship between pain and motivation to smoke as a function of smoking-related outcome expectancies and use of pain-coping behaviors.

\section{Pain-Coping Behaviors}

First, we propose that following the experience of situational pain, smokers who utilize effective pain-coping behaviors and strategies may experience reduced pain reactivity, which could, in turn, result in decreased motivation to smoke. The current results provide some support for this notion. For example, participants who were instructed to cope during pain induction were able to keep their hands submerged longer, reported suppressed craving, and demonstrated longer latencies to light a cigarette when given the opportunity to smoke. Future studies should determine which specific coping 
strategies are most helpful for reducing motivation to smoke in response to pain.

\section{Expectancies for Pain Coping/Reduction via Smoking}

Next, the model presented in Figure 2 indicates two points at which smokingrelated outcome expectancies may influence the casual pathway between pain and smoking motivation. First, among tobacco users, the initial utilization of pain coping behaviors may depend on the degree to which an individual believes that smoking will sufficiently diminish pain reactivity. That is, tobacco users who believe that smoking will provide an adequate pain coping solution may not engage or develop more adaptive coping strategies. Second, smokers who neglect to utilize pain coping behaviors or are unsuccessful in their employment of coping to curtail pain reactivity could, subsequently, experience increased motivation to smoke. This may be especially true for those tobacco users who hold strong expectancies that smoking will help them cope with or reduce pain. The current study focused only on the second point of intervention (bolded arrow in Figure 2) because participants were randomly assigned to either Coping Enhancement or No-Coping Enhancement conditions. Thus, the influence of smoking-related outcome expectancies on smokers' decisions to initiate pain coping behaviors could not be assessed because participants were not given the choice of whether or not to employ the distraction-based coping strategy. Nonetheless, the current results do provide some support for the hypothesis that an intervention component designed to reduce positive outcome expectancies that smoking can effectively help one cope with or reduce pain may result in decreased motivation to smoke in response to situational pain. Future research would benefit from examining the extent to which smokers' expectancies for 
pain coping/reduction via tobacco smoking may moderate (a) their decision to engage a more adaptive pain coping strategy, and (b) which forms of coping are employed (e.g., active vs. passive or cognitive vs. behavioral).

With regard to our expectation that smokers randomized to Coping Enhancement conditions would report less pain and keep their hand immersed in the cold water for longer than smokers randomized to No-Coping Enhancement conditions, results indicated that only the latter hypothesis was supported. One explanation for these findings may be that pain ratings were equivalent across Coping Enhancement and No-Coping Enhancement conditions because Coping Enhancement participants endured the cold pressor for longer than No-Coping Enhancement participants. That is, perhaps we would have observed expected group differences in pain ratings if not for the fact that Coping Enhancement smokers were exposed to the pain stimulus for significantly longer than No-Coping Enhancement smokers (albeit as a function of the coping task). Future studies should examine the effect of coping on pain-induced smoking motivation within the context of experimental pain modalities that allow researchers to equate the duration and quality of pain exposure across conditions (e.g., mechanical, electrical stimulation).

The main limitation of the current study is that although a controlled, laboratorybased experiment maximizes internal validity, there is a cost to external validity. Experimental pain is not equivalent to clinical pain, and the current design excluded smokers who suffer from chronic pain. Thus, these results may not generalize to smokers suffering from clinical pain disorders. However, we have no reason to believe that the theoretical inferences derived from the current study would be inapplicable to persons 
suffering from chronic or intermittent pain. It is also not unreasonable to consider that mechanisms similar to those studied herein might play an important role in the maintenance of tobacco smoking among clinical pain populations. These considerations notwithstanding, it is important to note that the current study represents a nascent step in a programmatic line of inquiry into pain as a motivator of smoking. Clearly, further research is needed to adequately address both internal and external validity requirements before drawing any firm conclusions. For example, the current experimental paradigm should be extended to persons living with chronically painful conditions. It would be important to determine whether pain patients have entrenched pain-smoking expectancies that would be more resistant to a brief laboratory manipulation. Pain patients may also be less reactive to laboratory-induced pain. It would also be useful to examine pain-related motivation to smoke in naturalistic (i.e., real-world) settings, perhaps using ecological momentary assessment (e.g., Stone \& Shiffman, 1994).

In addition, our brief manipulations are not equivalent to actual clinical interventions. For example, participants in the Coping Enhancement conditions utilized a distracting task that required them to listen to and repeat aloud letters presented through headphones. Although this coping strategy may appear somewhat artificial, with limited potential for real-world and clinical application, it did allow us to directly test a theoretical mechanism of interest (i.e., Does any form of coping influence the relationship between pain and increased smoking motivation?). Future investigations may build upon these findings by determining which forms of coping are most effective and appropriate, and assessing whether pain coping strategies currently in use by individuals 
with chronic conditions may influence the proposed pain-smoking association.

A third limitation is the possibility that experimenter demand may have influenced the current results, particularly as they relate to the Expectancy Challenge. For example, Expectancy Challenge participants were required to watch a video designed to reduce outcome expectancies that smoking can effectively help one cope with or reduce pain. Shortly thereafter, and following pain-induction, participants were asked to rate their desire to smoke and were given an opportunity to smoke one of their own cigarettes. Although it is plausible that Expectancy Challenge participants may have recognized that post-pain craving was hypothesized to decrease, we took several steps to mitigate and assess for potential demand. First, the experimental video presented only information for which there was empirical support. This approach is highly consistent with clinical psychoeducational interventions designed to improve patient understanding and enhance motivation to modify behavior. Second, the experimental video referred to relations between pain (particularly chronic pain) and tobacco smoking, in general. There was not mention of potential or anticipated associations between experimentally-induced acute pain and either smoking urge or smoking behavior. Third, relative to self-reported craving, it is more difficult to attribute observed group differences on the more objective, behavioral indices of smoking motivation (i.e., latency to smoke, number of puffs taken, and total time spent smoking) to demand effects. Finally, to determine whether participant tendencies towards impression management and desirable responding may have influenced the current findings, we reran our ANCOVAs with BIDR-IM scores as an added covariate. Analyses revealed no evidence of association between BIDR-IM 
scores and any of the outcomes reported herein (all $p s>.30$ ). Future studies should (a) attempt to reduce the potential for demand in manipulating smoking-related outcome expectancies, (b) examine how long such expectancy effects may last, and (c) determine how to increase their duration and enhance generalizability.

In summary, this study provides the first experimental evidence that constructs derived from social-cognitive theory may represent important mechanisms underlying the causal relationship between pain and motivation to smoke. Specifically, manipulations intended to (a) reduce positive outcome expectancies that smoking can effectively help one cope with or reduce pain, and (b) employ a distraction-based pain coping strategy enhanced with positive self-efficacy and outcome expectancy feedback, each resulted in reduced craving and increased latency to smoke, relative to controls. The primary strength of the current study is that it was designed to serve as an analogue test of theoretical mechanisms (as extrapolated from both the pain and smoking literature) that have the potential to influence the development of clinical interventions for persons with comorbid pain and substance use disorders. Like smoking, chronic pain is a critical national health problem. It has been estimated that up to 60 million Americans suffer from chronic pain (American Pain Society, 2003; Gallagher, 1999), and a recent nationwide survey revealed that more than half of all Americans experience either intermittent or chronic pain (Stanford University Medical Center, 2005). With future studies addressing both internal and external validity requirements, there is potential for the development of empirically grounded interventions for smokers in pain. 


\section{References}

Aamodt, A. H., Stovner, L. J., Hagen, K., Brathen, G., \& Zwart, J. (2006). Headache prevalence related to smoking and alcohol use. The Head-HUNT Study. European Journal of Neurology, 13(11), 1233-1238.

Albano, S. A., Santana-Sahagun, E., \& Weisman, M. H. (2001). Cigarette smoking and rheumatoid arthritis. Seminars in Arthritis and Rheumatism, 31(3), 146-159.

American Pain Society (2003). Principles of analgesic use in the treatment of acute pain and cancer pain (5th ed.). Glenview, IL: Author.

Bandura, A. (1977). Social Learning Theory. New York: General Learning Press.

Bandura, A. (1986). Social Foundations of Thought and Action: A Social Cognitive Theory. Englewood Cliffs, NJ: Prentice Hall.

Bandura, A., Cioffi, D., Taylor, C. B., \& Brouillard, M. E. (1988). Perceived self-efficacy in coping with cognitive stressors and opioid activation. Journal of Personality and Social Psychology, 55(3), 479-488.

Brandon, T. H., \& Baker, T. B. (1991). The Smoking Consequences Questionnaire: The subjective expected utility of smoking in college students. Psychological Assessment, 3(3), 484-491.

Brandon, T. H., Herzog, T. A., Irvin, J. E., \& Gwaltney, C. J. (2004). Cognitive and social learning models of drug dependence: implications for the assessment of tobacco dependence in adolescents. Addiction, 99 Suppl 1, 51-77. 
Brandon, T. H., Juliano, L. M., \& Copeland, A. C. (1999). Expectancies for tobacco smoking. In I. Kirsch (Ed.), How expectancies shape experience (pp. 263-299). Washington, DC: American Psychological Association.

Brandon, T. H., Wetter, D. W., \& Baker, T. B. (1996). Affect, expectancies, urges, and smoking: Do they conform to models of drug motivation and relapse? Experimental and Clinical Psychopharmacology, 4(1), 29-36.

Byrne, D. (1961). The repression-sensitization scale: rationale, reliability, and validity. Journal of Personality, 29, 334-349.

CDC (2008a). Cigarette Smoking Among Adults - United States, 2007. Morbidity and Mortality Weekly Report, 57(45), 1221-1226. Retrieved from http://www.cdc.gov/mmwr/preview/mmwrhtml/mm5745a2.htm

CDC (2008b). Smoking-Attributable Mortality, Years of Potential Life Lost, and Productivity Losses - United States, 2000-2004. Morbidity and Mortality Weekly Report, 57(45), 1226-1228.

Cohen, J. (1988). Statistical power analysis for the behavioral sciences (2nd Ed.). Hillsdale, NJ: Erlbaum.

Cooper, M. L., Russell, M., \& George, W. H. (1988). Coping, expectancies, and alcohol abuse: a test of social learning formulations. Journal of Abnormal Psychology, $97(2), 218-230$.

Copeland, A. L., \& Brandon, T. H. (2000). Testing the causal role of expectancies in smoking motivation and behavior. Addictive Behaviors, 25(3), 445-449. 
Cox, L. S., Tiffany, S. T., \& Christen, A. G. (2001). Evaluation of the brief questionnaire of smoking urges (QSU-brief) in laboratory and clinical settings. Nicotine and Tobacco Research, 3(1), 7-16.

Davidson, M., Davidson, P., Tripp, D., \& Borshch, Y. (2005). Cigarette smoking and chronic pain: Relationship to pain severity and affective distress. The Journal of Pain, 6(3, Supplement 1), S61-S61.

Devine, D. P., \& Spanos, N. P. (1990). Effectiveness of maximally different cognitive strategies and expectancy in attenuation of reported pain. Journal of Personality and Social Psychology, 58(4), 672-678.

Ditre, J. W., \& Brandon, T. H. (2008). Pain as a motivator of smoking: effects of pain induction on smoking urge and behavior. Journal of Abnormal Psychology, $117(2), 467-472$.

Ditre, J. W., \& Brandon, T. H. (under review). Pain, Nicotine, and Smoking: Research Findings and Theoretical Considerations.

Ditre, J. W., Gonzalez, B. D., Simmons, V. N., Faul, L., Jacobsen, P. B., \& Brandon, T. H. (under review). Associations between pain and smoking status among cancer patients.

Dworkin, R. H., Turk, D. C., Farrar, J. T., Haythornthwaite, J. A., Jensen, M. P., Katz, N. P., et al. (2005). Core outcome measures for chronic pain clinical trials: IMMPACT recommendations. Pain, 113(1-2), 9-19.

Eriksen, W. B., Brage, S., \& Bruusgaard, D. (1997). Does smoking aggravate musculoskeletal pain? Scandinavian Journal of Rheumatology, 26(1), 49-54. 
Fertig, J. B., Pomerleau, O. F., \& Sanders, B. (1986). Nicotine-produced antinociception in minimally deprived smokers and ex-smokers. Addictive Behaviors, 11(3), 239248.

Fiore, M. C., Jaen, C. R., Baker, T. B., Bailey, W. C., Benowitz, N. L., Curry, S. J., et al. (2008). Treating Tobacco Use and Dependence: 2008 Update. Clinical Practice Guideline. Rockville, MD: U.S. Department of Health and Human Services. Public Health Service. May 2008.

Fishbain, D. A., Lewis, J. E., Cole, B., Cutler, R. B., Rosomoff, H. L., \& Rosomoff, R. S. (2007). Variables associated with current smoking status in chronic pain patients. Pain Medicine, 8(4), 301-311.

Gallagher, R. M. (1999). Primary care and pain medicine. A community solution to the public health problem of chronic pain. Medical Clinics of North America, 83(3), $555-583$, v.

Girdler, S. S., Maixner, W., Naftel, H. A., Stewart, P. W., Moretz, R. L., \& Light, K. C. (2005). Cigarette smoking, stress-induced analgesia and pain perception in men and women. Pain, 114(3), 372-385.

Goldman, M. S. (1999). Expectancy operation: Cognitive-neural models and architectures. In I. Kirsch (Ed.), How expectancies shape experience (pp. 41-63). Washington, DC: American Psychological Association.

Goldman, M. S. (2002). Expectancy and risk for alcoholism: the unfortunate exploitation of a fundamental characteristic of neurobehavioral adaptation. Alcoholism, Clinical and Experimental Research, 26(5), 737-746. 
Hahn, E. J., Rayens, M. K., Kirsh, K. L., \& Passik, S. D. (2006). Brief report: Pain and readiness to quit smoking cigarettes. Nicotine \& Tobacco Research, 8(3), 473480.

Haythornthwaite, J. A., Menefee, L. A., Heinberg, L. J., \& Clark, M. R. (1998). Pain coping strategies predict perceived control over pain. Pain, 77(1), 33-39.

Heatherton, T. F., Kozlowski, L. T., Frecker, R. C., \& Fagerstrom, K. O. (1991). The Fagerstrom Test for Nicotine Dependence: a revision of the Fagerstrom Tolerance Questionnaire. British Journal of Addiction, 86(9), 1119-1127.

Heishman, S. J. (1999). Behavioral and cognitive effects of smoking: relationship to nicotine addiction. Nicotine and Tobacco Research, 1 Suppl 2, S143-147; discussion S165-146.

Jamison, R. N., Stetson, B. A., \& Parris, W. C. (1991). The relationship between cigarette smoking and chronic low back pain. Addictive Behaviors, 16(3-4), 103-110.

Jamner, L. D., Girdler, S. S., Shapiro, D., \& Jarvik, M. E. (1998). Pain inhibition, nicotine, and gender. Experimental and Clinical Psychopharmacology, 6(1), 96106.

Jarvik, M. E., Caskey, N. H., Rose, J. E., Herskovic, J. E., \& Sadeghpour, M. (1989). Anxiolytic effects of smoking associated with four stressors. Addictive Behaviors, 14(4), 379-386.

Jensen, M. P., Turner, J. A., \& Romano, J. M. (1991). Self-efficacy and outcome expectancies: relationship to chronic pain coping strategies and adjustment. Pain, 44(3), 263-269. 
Kassel, J. D., Stroud, L. R., \& Paronis, C. A. (2003). Smoking, stress, and negative affect: correlation, causation, and context across stages of smoking. Psychological Bulletin, 129(2), 270-304.

Keefe, F. J., Kashikar-Zuck, S., Robinson, E., Salley, A., Beaupre, P., Caldwell, D., et al. (1997). Pain coping strategies that predict patients' and spouses' ratings of patients' self-efficacy. Pain, 73(2), 191-199.

Keogh, E., Hatton, K., \& Ellery, D. (2000). Avoidance versus focused attention and the perception of pain: differential effects for men and women. Pain, 85(1-2), 225230.

Marino, J., Gwynn, M. I., \& Spanos, N. P. (1989). Cognitive mediators in the reduction of pain: the role of expectancy, strategy use, and self-presentation. Journal of Abnormal Psychology, 98(3), 256-262.

Marlatt, G. A., \& Gordon, J. R. (1985). Relapse Prevention. New York: Guilford Press.

Michna, E., Ross, E. L., Hynes, W. L., Nedeljkovic, S. S., Soumekh, S., Janfaza, D., et al. (2004). Predicting aberrant drug behavior in patients treated for chronic pain: importance of abuse history. Journal of Pain and Symptom Management, 28(3), $250-258$.

Palmer, K. T., Syddall, H., Cooper, C., \& Coggon, D. (2003). Smoking and musculoskeletal disorders: findings from a British national survey. Annals of the Rheumatic Diseases, 62(1), 33-36. 
Paulhus, D. L., Robinson, J. P., Shaver, P. R., \& Wrightsman, L. S. (1991). Measurement and control of response bias Measures of personality and social psychological attitudes. (pp. 17-59). San Diego, CA, US: Academic Press.

Payne, T. J., Stetson, B., Stevens, V. M., Johnson, C. A., Penzien, D. B., \& Van Dorsten, B. (1991). The impact of cigarette smoking on headache activity in headache patients. Headache, 31(5), 329-332.

Pomerleau, O. F. (1986). Nicotine as a psychoactive drug: anxiety and pain reduction. Psychopharmacology Bulletin, 22(3), 865-869.

Preacher, K. J., \& Hayes, A. F. (2004). SPSS and SAS procedures for estimating indirect effects in simple mediation models. Behavior Research Methods, Instruments, \& Computers, 36(4), 717-731.

Rainville, P., Feine, J. S., Bushnell, M. C., \& Duncan, G. H. (1992). A psychophysical comparison of sensory and affective responses to four modalities of experimental pain. Somatosensory and Motor Research, 9(4), 265-277.

Riley, J. L., 3rd, Tomar, S. L., \& Gilbert, G. H. (2004). Smoking and smokeless tobacco: increased risk for oral pain. Journal of Pain, 5(4), 218-225.

Rokke, P. D., Fleming-Ficek, S., Siemens, N. M., \& Hegstad, H. J. (2004). Self-efficacy and choice of coping strategies for tolerating acute pain. Journal of Behavioral Medicine, 27(4), 343-360.

Rosenstiel, A. K., \& Keefe, F. J. (1983). The use of coping strategies in chronic low back pain patients: relationship to patient characteristics and current adjustment. Pain, 17(1), 33-44. 
Silverstein, B. (1982). Cigarette smoking, nicotine addiction, and relaxation. Journal of Personality and Social Psychology, 42(5), 946-950.

Stanford University Medical Center (2005). Physical Pain Aggravates Majority Of Americans, According To Poll Retrieved November 4, 2008, from http://www.sciencedaily.com/releases/2005/05/050509171112.htm

Steele, C. M., \& Josephs, R. A. (1990). Alcohol myopia. Its prized and dangerous effects. American Psychologist, 45(8), 921-933.

Stone, A. A., \& Shiffman, S. (1994). Ecological Momentary Assessment (EMA) in behavioral medicine. Annals of Behavioral Medicine, 16, 199-202.

Waldie, K. E., McGee, R., Reeder, A. I., \& Poulton, R. (2008). Associations between frequent headaches, persistent smoking, and attempts to quit. Headache, 48(4), $545-552$.

Watson, D., Clark, L. A., \& Tellegen, A. (1988). Development and validation of brief measures of positive and negative affect: the PANAS scales. Journal of Personality and Social Psychology, 54(6), 1063-1070.

Wills, T. A., \& Hirky, A. E. (1996). Coping and substance abuse. In M. Zeidner \& N. S. Endler (Eds.), Handbook of Coping: Theory, Research, and Applications (pp. 279-302). New York: Wiley.

Zvolensky, M. J., McMillan, K., Gonzalez, A., \& Asmundson, G. J. (2009). Chronic pain and cigarette smoking and nicotine dependence among a representative sample of adults. Nicotine and Tobacco Research. 
Appendices 


\section{Appendix A: Questionnaire of Smoking Urges-Brief}

Indicate how much you agree or disagree with each of the following statements by marking one of the circles between STRONGLY DISAGREE and STRONGLY AGREE. The closer you place your mark to one end or the other indicates the strength of your agreement or disagreement. We are interested in how you are thinking and feeling $\underline{\text { right now }}$ as you are filling out the questionnaire.

1. I have a desire for a cigarette right now.
STRONGLY
DISAGREE
$\mathrm{O}$
$\mathrm{O}$
$\mathrm{O}$
$\mathrm{O}$
$\mathrm{O}$
$\mathrm{O}$
STRONGLY AGREE

2. Nothing would be better than smoking a cigarette right now.
STRONGLY
DISAGREE
$\mathrm{O}$
$\mathrm{O}$
$\mathrm{O}$
$\mathrm{O}$
$\mathrm{O}$
$\mathrm{O}$
STRONGLY
AGREE

3. If it were possible, I probably would smoke now.
STRONGLY
DISAGREE
$\mathrm{O} \quad \mathrm{O}$
$\mathrm{O}$
$\mathrm{O}$
$\mathrm{O}$
STRONGLY
AGREE

4. I could control things better right now if I could smoke.
STRONGLY
DISAGREE
$\mathrm{O}$
$\mathrm{O} \quad \mathrm{O}$
$\mathrm{O}$
$\mathrm{O}$
$\mathrm{O}$
STRONGLY
AGREE

5. All I want right now is a cigarette.
STRONGLY
$\mathrm{O}-\mathrm{O} \quad \mathrm{O}$
O $\quad 0$
0
$\mathrm{O} \quad \mathrm{O} \quad \mathrm{O}$
STRONGLY
DISAGREE

(a)

6. I have an urge for a cigarette.
STRONGLY
DISAGREE
$\mathrm{O} \quad \mathrm{O}$
7. A cigarette would taste good right now.

$\mathrm{O}$

$\mathrm{O}$

$\mathrm{O}$

$\mathrm{O}$

STRONGLY

AGREE

\section{STRONGLY}

DISAGREE
$\mathrm{O}$
$\mathrm{O}$

$\mathrm{O}$

$\mathrm{O}$

$\mathrm{O}$

$\mathrm{O}$

STRONGLY AGREE

8. I would do almost anything for a cigarette now.

STRONGLY

DISAGREE

$\mathrm{O} \quad \mathrm{O}$

$\mathrm{O} \quad \mathrm{O}$

$\mathrm{O}$

$\mathrm{O}$

$\mathrm{O}$

$\mathrm{O}$

STRONGLY AGREE

9. Smoking would make me less depressed.

STRONGLY

DISAGREE

$\mathrm{O}$

$\mathrm{O}$

$\mathrm{O}$

$\mathrm{O}$

$\mathrm{O}$

$\mathrm{O}$

$\mathrm{O}$

STRONGLY AGREE

10. I am going to smoke as soon as possible.

STRONGLY

DISAGREE

$\mathrm{O}$

$\mathrm{O}$

$\mathrm{O}$

$\mathrm{O}$

O

$\mathrm{O}$

$\mathrm{O}$

STRONGLY AGREE 


\section{Appendix B: Pain and Smoking Expectancies Measure}

INSTRUCTIONS: Below is a list of statements about smoking. Each statement contains a possible consequence of smoking. For each of the statements listed below, please rate how LIKELY or UNLIKELY you believe each consequence is for you when you smoke. If the consequence seems UNLIKELY to you, mark a number from 0-4. If the consequence seems LIKELY to you, mark a number from 5-9.

That is, if you believe that a consequence would never happen, mark the 0 ; if you believe a consequence would happen every time you smoke, mark the number 9 . Use the guide below to aid you further:

\begin{tabular}{|c|c|c|c|c|c|c|c|c|c|}
\hline 0 & 1 & 2 & 3 & 4 & 5 & 6 & 7 & 8 & 9 \\
\hline Completely & Extremely & Very & Somewhat & Little & Little & Somewhat & Very & Extremely & Completely \\
\hline
\end{tabular}

1. Smoking would ease my pain if I were hurting.

$\begin{array}{llllllllll}0 & 1 & 2 & 3 & 4 & 5 & 6 & 7 & 8 & 9\end{array}$

2. If I were to experience pain, a cigarette would help reduce it.

$\begin{array}{llllllllll}0 & 1 & 2 & 3 & 4 & 5 & 6 & 7 & 8 & 9\end{array}$

3. If I hurt myself, I would feel less pain if I could smoke.

$\begin{array}{llllllllll}0 & 1 & 2 & 3 & 4 & 5 & 6 & 7 & 8 & 9\end{array}$

4. When I feel pain, a cigarette can really help.

$\begin{array}{llllllllll}0 & 1 & 2 & 3 & 4 & 5 & 6 & 7 & 8 & 9\end{array}$

5. I feel like smoking would help me cope with pain.

$\begin{array}{llllllllll}0 & 1 & 2 & 3 & 4 & 5 & 6 & 7 & 8 & 9\end{array}$ 


\section{Appendix C: Perceived Self-Efficacy to Manage Pain}

Scale 1: Please indicate how confident you are that you will be able to keep your hand in the cold water for each amount of time listed below by circling any of the numbers between $100 \%$ confidence and $0 \%$ confidence. Please stop circling when you reach $0 \%$ confidence.

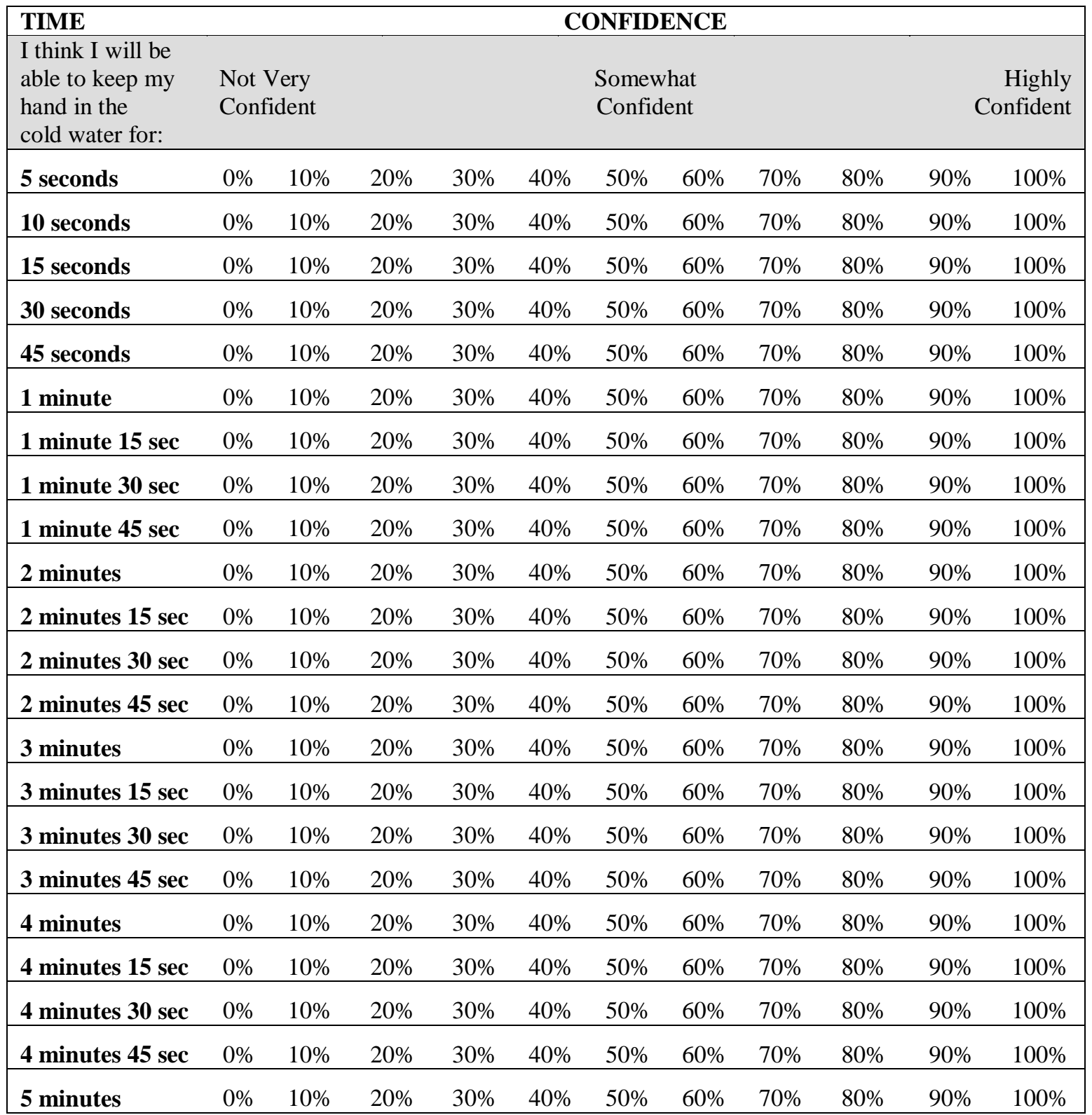




\section{Appendix C: (Continued)}

Scale 2: People sometimes do things to reduce (or cope with) their pain without taking medication. Please indicate your degree of confidence to reduce (or cope with) the different types of pain you might feel from placing your hand in the cold water.

\begin{tabular}{|c|c|c|c|c|c|c|c|c|c|c|c|}
\hline \multicolumn{12}{|c|}{ CONFIDENCE TO REDUCE (OR COPE WITH) DIFFERENT TYPES OF PAIN } \\
\hline & \multicolumn{4}{|c|}{ Not Very Confident } & \multicolumn{4}{|c|}{ Somewhat Confident } & \multicolumn{3}{|c|}{ Highly Confiden } \\
\hline \multicolumn{12}{|l|}{ If I felt a DULL PAIN... } \\
\hline $\begin{array}{l}\text {...I could reduce it by at } \\
\text { least a small amount } \\
\text { (some coping) }\end{array}$ & $0 \%$ & $10 \%$ & $20 \%$ & $30 \%$ & $40 \%$ & $50 \%$ & $60 \%$ & $70 \%$ & $80 \%$ & $90 \%$ & $100 \%$ \\
\hline $\begin{array}{l}\text {...I could reduce it by at } \\
\text { least a moderate amount } \\
\text { (moderate coping) }\end{array}$ & $0 \%$ & $10 \%$ & $20 \%$ & $30 \%$ & $40 \%$ & $50 \%$ & $60 \%$ & $70 \%$ & $80 \%$ & $90 \%$ & $100 \%$ \\
\hline $\begin{array}{l}\text {...I could reduce it by at } \\
\text { least a large amount } \\
\text { (excellent coping) }\end{array}$ & $0 \%$ & $10 \%$ & $20 \%$ & $30 \%$ & $40 \%$ & $50 \%$ & $60 \%$ & $70 \%$ & $80 \%$ & $90 \%$ & $100 \%$ \\
\hline
\end{tabular}

\begin{tabular}{|c|c|c|c|c|c|c|c|c|c|c|c|}
\hline \multicolumn{12}{|c|}{ If I felt an ACHING PAIN... } \\
\hline $\begin{array}{l}\text {...I could reduce it by at } \\
\text { least a small amount } \\
\text { (some coping) }\end{array}$ & $0 \%$ & $10 \%$ & $20 \%$ & $30 \%$ & $40 \%$ & $50 \%$ & $60 \%$ & $70 \%$ & $80 \%$ & $90 \%$ & $100 \%$ \\
\hline $\begin{array}{l}\text {...I could reduce it by at } \\
\text { least a moderate amount } \\
\text { (moderate coping) }\end{array}$ & $0 \%$ & $10 \%$ & $20 \%$ & $30 \%$ & $40 \%$ & $50 \%$ & $60 \%$ & $70 \%$ & $80 \%$ & $90 \%$ & $100 \%$ \\
\hline $\begin{array}{l}\text {...I could reduce it by at } \\
\text { least a large amount } \\
\text { (excellent coping) }\end{array}$ & $0 \%$ & $10 \%$ & $20 \%$ & $30 \%$ & $40 \%$ & $50 \%$ & $60 \%$ & $70 \%$ & $80 \%$ & $90 \%$ & $100 \%$ \\
\hline
\end{tabular}

\begin{tabular}{|l|lllllllllll|}
\hline If I felt a PENETRATING PAIN... & & & & & & & & & & \\
\hline $\begin{array}{l}\ldots \text { I could reduce it by at } \\
\text { least a small amount } \\
\text { (some coping) }\end{array}$ & $0 \%$ & $10 \%$ & $20 \%$ & $30 \%$ & $40 \%$ & $50 \%$ & $60 \%$ & $70 \%$ & $80 \%$ & $90 \%$ & $100 \%$ \\
\hline $\begin{array}{l}\ldots \text { I could reduce it by at } \\
\text { least a moderate amount } \\
\text { (moderate coping) }\end{array}$ & $0 \%$ & $10 \%$ & $20 \%$ & $30 \%$ & $40 \%$ & $50 \%$ & $60 \%$ & $70 \%$ & $80 \%$ & $90 \%$ & $100 \%$ \\
$\begin{array}{l}\ldots I \text { could reduce it by at } \\
\text { least a large amount } \\
\text { (excellent coping) }\end{array}$ & $0 \%$ & $10 \%$ & $20 \%$ & $30 \%$ & $40 \%$ & $50 \%$ & $60 \%$ & $70 \%$ & $80 \%$ & $90 \%$ & $100 \%$ \\
\hline
\end{tabular}




\section{Appendix C: (Continued)}

\begin{tabular}{|c|c|c|c|c|c|c|c|c|c|c|c|}
\hline \multicolumn{12}{|c|}{ If I felt an EXCRUCIATING PAIN... } \\
\hline $\begin{array}{l}\text {..I could reduce it by at } \\
\text { least a small amount } \\
\text { (some coping) }\end{array}$ & $0 \%$ & $10 \%$ & $20 \%$ & $30 \%$ & $40 \%$ & $50 \%$ & $60 \%$ & $70 \%$ & $80 \%$ & $90 \%$ & $100 \%$ \\
\hline $\begin{array}{l}\text {...I could reduce it by at } \\
\text { least a moderate amount } \\
\text { (moderate coping) }\end{array}$ & $0 \%$ & $10 \%$ & $20 \%$ & $30 \%$ & $40 \%$ & $50 \%$ & $60 \%$ & $70 \%$ & $80 \%$ & $90 \%$ & $100 \%$ \\
\hline $\begin{array}{l}\text {...I could reduce it by at } \\
\text { least a large amount } \\
\text { (excellent coping) }\end{array}$ & $0 \%$ & $10 \%$ & $20 \%$ & $30 \%$ & $40 \%$ & $50 \%$ & $60 \%$ & $70 \%$ & $80 \%$ & $90 \%$ & $100 \%$ \\
\hline
\end{tabular}


Appendix D: Positive and Negative Affect Schedule

This scale consists of a number of words that describe different feelings and emotions. Read each item and then mark the appropriate answer in the space next to that word. Indicate to what extent you feel this way at this moment. Use the following scale to record your answers.

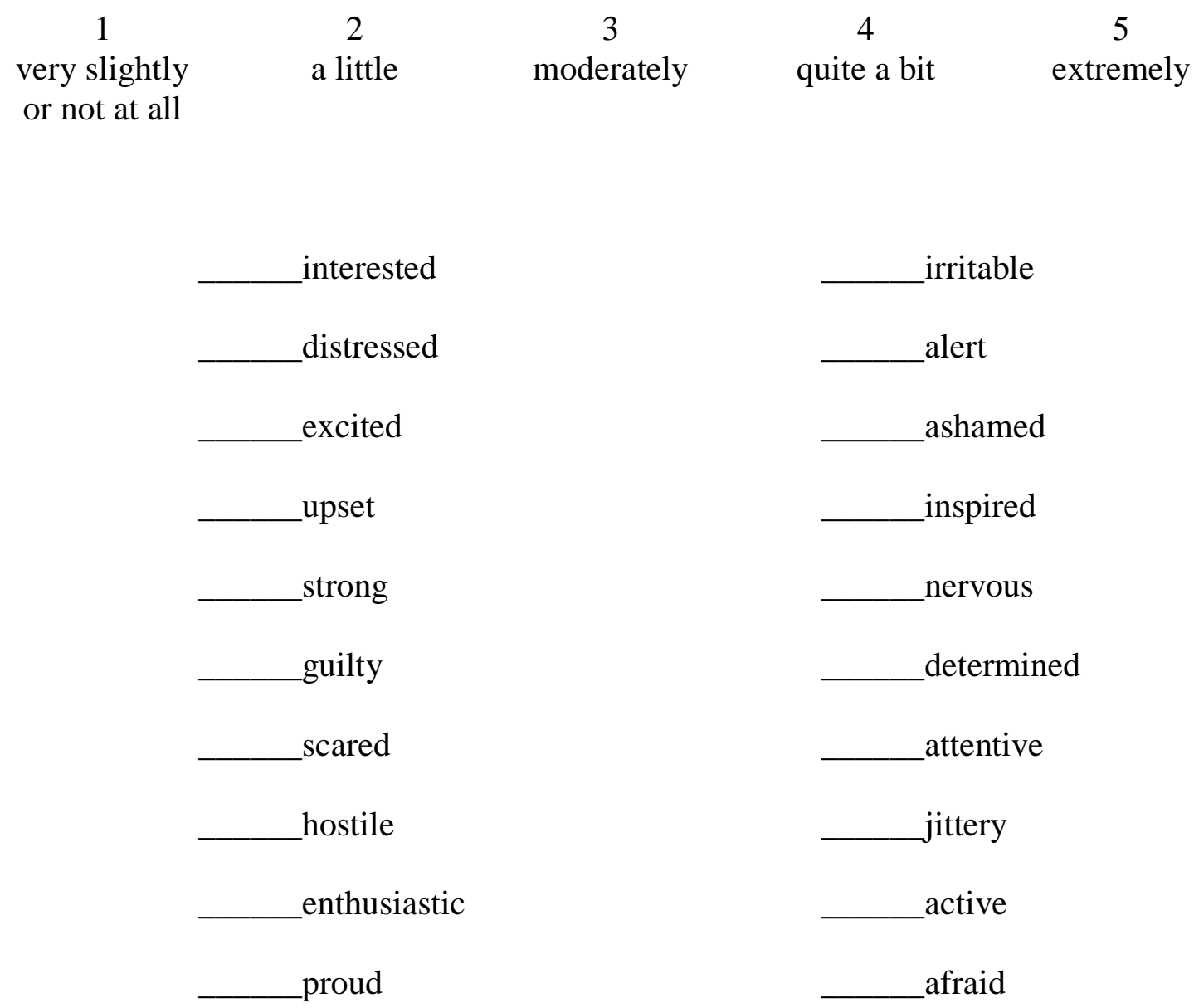




\section{Appendix E: Balanced Inventory of Desirable Responding - IM}

Indicate the extent to which you agree or disagree with the following statements using the scale below.

\begin{tabular}{|c|c|c|c|c|c|c|}
\hline 1 & 2 & 3 & 4 & 5 & 6 & 7 \\
\hline Not True & \multicolumn{3}{|c|}{ Somewhat True } & & Very True \\
\hline
\end{tabular}

1) I sometimes tell lies if I have to.

1234567

2) I never cover up my mistakes.

12345567

3) There have been occasions when I have taken advantage of someone.

1234567

4) I never swear.

1234567

5) I sometimes try to get even rather than forgive and forget.

1234567

6) I always obey laws, even if I'm unlikely to get caught.

1234567

7) I have said something bad about a friend behind his or her back.

1234567

8) When I hear people talking privately, I avoid listening.

123345667

9) I have received too much change from a salesperson without telling him or her.

1234567

10) I always declare everything at customs.

1234567

11) When I was young I sometimes stole things.

1234567

12) I have never dropped litter on the street.

1234567

13) I sometimes drive faster than the speed limit.

1234567

14) I never read sexy books or magazines.

1234567

15) I have done things that I don't tell other people about.

1234567

16) I never take things that don't belong to me.

1234567

17) I have taken sick-leave from work or school even though $I$ wasn't really sick.

18) I have never damaged a library book or store merchandise without reporting it.

19) I have some pretty awful habits.

1234567

20) I don't gossip about other people's business. 


\section{Appendix F: Bogus Personality Measure}

Listed below are a number of statements concerning personal attitudes and traits. Read each item and decide whether the statement is true or false as it pertains to you, personally.

1. $\mathrm{T}$ F My hardest battles are with myself.

2. $\mathrm{T}$ F I have several times given up doing a thing because I thought too little of my ability.

3. $\mathrm{T}$ F I am easily embarrassed.

4. $\mathrm{T}$ F I have had no difficulty in keeping my balance in walking.

5. $\mathrm{T} \quad \mathrm{F}$ I find it hard to keep my mind on a task or job.

6. $\mathrm{T} \quad \mathrm{F}$ I am apt to pass up something I want to do because others feel that I am not going about it in the right way.

7. $\mathrm{T} F$ I believe I am no more nervous than most others.

8. $\mathrm{T} \quad \mathrm{F}$ I have more trouble concentrating than others seem to have.

9. $\mathrm{T} \quad \mathrm{F}$ I have few or no pains.

10. T F I do not tire quickly. 
Appendix G: Numerical Rating Scale

Please put a circle around the number that best describes your pain, at its worst, since placing your hand in the water.

*Note: 0 means 'No pain' and 10 means 'Pain as bad as you can imagine'

No pain $\begin{array}{llllllllllll}\text { Pain as bad } \\ \text { as you can } \\ \text { imagine }\end{array}$




\section{Appendix H: Smoking Status Questionnaire}

1. Date of Birth:

Month Day Year

2. Sex: (check one) $\square$ Male $\square$ Female

3. Do you smoke cigarettes everyday? $\square$ Yes $\square$ No If No, stop here; If Yes, please continue

4. How many years have you been smoking daily?

5. How many cigarettes do you smoke per day on average?

6. Do you inhale? (circle one) NEVER SOMETIMES ALWAYS

7. Do you smoke more during the first two hours of the day than during the rest of the day? $\square$ Yes $\square$ No

8. How soon after you wake up do you smoke your first cigarette?

$\square$ Within 5 minutes

$\square$ 6-30 minutes

$\square$ 31-60 minutes

$\square$ After 60 minutes

9. Which of all the cigarettes you smoke would you most hate to give up?

$\square$ The first one in the morning

$\square$ The one with breakfast

$\square$ The one with lunch

$\square$ The one with dinner

$\square$ The last cigarette before going to bed

$\square$ Other:

10. Do you find it difficult to refrain from smoking in places where it is forbidden (eg. in church, at the library)? $\square$ Yes $\square$ No

11. Do you smoke if you are so ill that you are in bed most of the day?

$\square$ Yes $\square$ No 


\section{Appendix I: Demographic Questionnaire}

The following questions are about yourself and your life situation. All answers will be kept confidential.

1. Gender: (check one) $\square$ Male $\square$ Female

2. What is your age?

3. Date of Birth: $\overline{\text { Month }} \frac{/}{\text { Day }} \frac{/}{\text { Year }}$

4. What is your marital status?
a Single
a Married
a Separated
口 Divorced
a Widowed

5. With which racial category do you most identify yourself? (please check one)

- American Indian/Alaska Native

- Asian

a Native Hawaiian or Other Pacific Islander

- Black or African American

a White

6. Are you Hispanic/Latino?

a Yes

№

7. What is the highest grade level you have completed?

口 Did not graduate high school

a High school graduate

a Some college

- Technical school/Associates degree

- 4-year college degree

口 Some school beyond 4-year college degree

口 Professional degree (e.g. $\mathrm{MD}, \mathrm{JD}, \mathrm{PhD}$ )

8. What is your total household income?
- Under $\$ 10,000$
$\$ 10,000-\$ 19,999$
口 $\$ 20,000-\$ 29,999$
口 $\$ 30,000-\$ 39,999$
$ $\$ 40,000-\$ 49,999$
口 $\$ 50,000-\$ 59,999$
a $\$ 60,000-\$ 69,999$
$\$ 70,000-\$ 79,999$
- $\$ 80,000$ - $\$ 89,999$
口 Over $\$ 90,000$ 


\begin{abstract}
About the Author
Joseph W. Ditre received a Bachelor's Degree in Psychology from Binghamton University in 1998. He entered the Ph.D. program in Clinical Psychology at the University of South Florida in 2004.

While in the Ph.D. program at the University of South Florida, Mr. Ditre participated in research activities at the Tobacco Research and Intervention Program, and served as a therapist in the Psychological Services Center. Under the supervision of his advisor, Dr. Thomas Brandon, he coauthored several publications and made many presentations at national conferences.
\end{abstract}

